\title{
Characteristics of Direct Shear and Particle Breakage of Pebble Gravel Materials
}

\author{
Chenjie Hong, ${ }^{1}$ Man Huang $\mathbb{D}^{1},{ }^{1}$ Danyu Zhang, ${ }^{1}$ Pingshan Shou, ${ }^{2}$ and Zhiyong Zhu ${ }^{3}$ \\ ${ }^{1}$ Department of Civil Engineering, Shaoxing University, 508 Huancheng West Road, Shaoxing 312000, China \\ ${ }^{2}$ Ningbo Engineering Prospecting Institute, 206 Baoshan Road, Ningbo 315012, China \\ ${ }^{3}$ Zhejiang Institute of Hydrogeology and Engineering Geology, Ningbo, 501 Liyuan South Road, Ningbo 315010, China
}

Correspondence should be addressed to Man Huang; hmcadx@126.com

Received 2 June 2020; Revised 14 July 2020; Accepted 16 July 2020; Published 4 August 2020

Academic Editor: Hang Lin

Copyright (c) 2020 Chenjie Hong et al. This is an open access article distributed under the Creative Commons Attribution License, which permits unrestricted use, distribution, and reproduction in any medium, provided the original work is properly cited.

Particle size is an important factor affecting the Thermal-Hydraulic-Mechanical (THM) coupling behavior of graveled rock mass, especially for the shear mechanical properties. In this study, three groups of the particle size range and nine particle grading samples are designed for a large-scale direct shear test. The relationships between shear stress and shear displacement, shear strength, stress ratio, shear strength parameters, and particle breakage of pebble gravel are analyzed. The influence of particle size range and grade on the strength and particle breakage of gravel material is discussed. Results show evident particle breakage in the process of direct shear, and the degree of fragmentation is controlled by the normal load and the particle size distribution of the sample. The shear strength of the sample is no longer applicable to Mohr-Coulomb strength theory because of particle breakage that is more in line with the power function relationship. Shear strength of pebble gravel material has scale effect, and a corresponding relationship model between friction coefficient $f$ of material and characteristic particle size of the sample is proposed.

\section{Introduction}

Research on the mechanical properties of intact rock, including compressive strength, shear strength, and tensile strength, has achieved many results through large number of tests in recent years [1-8]. Among them, the shear strength as the most widely studied mechanical parameter has been predicted by the models of shear strength and normal stress, such as JRC-JCS model [9], Grasselli model [10], and Xia model [11]. However, the above models are mostly for intact materials and rarely involve unconsolidated sediments. As a product of geological history, the broken rock mass has not been deeply studied on mechanical properties, especially the pebble gravel widely distributed worldwide. Pebble gravel material is heterogeneous and discontinuous, and the contact form among particles is generally the point contact $[12,13]$. The engineering properties are different from those of sand and rock mass [14], which are affected by factors, such as shape parameters (size, sphericity, elongation, flatness, and slenderness) [15-17] and grading [18].
The maximum particle size of the pebble involved in the project can reach tens of centimeters, and even large-scale test instruments cannot test the prototype graded materials. Therefore, many scholars attempt to build particle grading samples in accordance with the requirements of the indoor test by a certain scale method and calculate the mechanical parameters of the original graded gravel. These scholars explore the corresponding laws of the mechanical parameters and particle size of the gravel within the measurable range. Buffington et al. analyzed the friction angle of the pebble layer on the surface of the natural river bed and pointed out that friction angle distributions can be expressed as a function of test grain size, median bed grain size, and bed sorting parameter [19]. Tuitz et al. proposed that particle size distribution has a certain effect on the loading condition of pebbles and ultimately affects the shear strength of the material [20]. Zhao et al. studied different scale methods. The effects on the macromechanical properties and mesomechanical responses of numerical samples were discussed, and the relationship between the fractal properties of the 
TABLE 1: Pebble gravel sample preparation.

\begin{tabular}{|c|c|c|c|c|c|}
\hline \multirow{2}{*}{ Group } & & \multicolumn{4}{|c|}{ Mass percentage of each particle group (\%) } \\
\hline & & $(60-40 \mathrm{~mm})$ & $(40-20 \mathrm{~mm})$ & $(20-10 \mathrm{~mm})$ & $(10-5 \mathrm{~mm})$ \\
\hline \multirow{3}{*}{ I: large particle size group } & $\mathrm{I}-1$ & 25 & 75 & - & - \\
\hline & $\mathrm{I}-2$ & 50 & 50 & - & - \\
\hline & $\mathrm{I}-3$ & 75 & 25 & - & - \\
\hline \multirow{3}{*}{ II: medium particle size group } & II-1 & - & 25 & 75 & - \\
\hline & $\mathrm{II}-2$ & - & 50 & 50 & - \\
\hline & II-3 & - & 75 & 25 & - \\
\hline \multirow{3}{*}{ III: small particle size group } & III-1 & - & - & 25 & 75 \\
\hline & III-2 & - & - & 50 & 50 \\
\hline & III-3 & - & - & 75 & 25 \\
\hline
\end{tabular}

gradation distribution of rockfill particles and the mechanical properties of numerical samples was discussed [21]. Wu et al. found that the shear strength effect of coarse granules is related to the sample preparation standard [22]. Under the same dry density sample preparation standards, friction angle and deformation modulus decrease with the increase of maximum particle size.

In the above studies, the samples are mostly reduced in the entire particle size range, whereas for the particles with a small size range, they can only be replaced by sand or even silt after the scale reduction, which is quite different from the properties of the original materials. After the reduction, the gravel content of the samples is reduced, and the soil content is increased; hence, controlling the particle grading as the only variable is impossible. In this study, three groups of the particle size range and nine particle grading samples are designed. The influence of particle size on the strength of pebble gravel materials is explored through a large-scale direct shear test. The particle size effect of the shear strength of the gravel material is discussed. Furthermore, the relationship model between the shear strength parameters and the characteristic particle size of the sample is established, and the particle crushing characteristics of the material are studied. To sum up, this study provides a method for the shear strength characteristic research of pebble gravel material, and the proposed model can be used to predict the shear strength of the material with different particle gradation.

\section{Methodology}

2.1. Test Groups. Pebble gravel materials used in the experiment are from the geological outcrop of Mianniushan, Ninghai County, Zhejiang, China. The protolith mainly consists of a tuff and part of basalt. The particles are screened after drying the pebble gravel materials to a constant weight. The particle size of the sample is divided into three ranges: large $(60-40 \mathrm{~mm})$, medium $(40-10 \mathrm{~mm})$, and small $(20-$ $5 \mathrm{~mm}$ ) particle size groups. Nine samples with a different particle grading are formed by adjusting the percentage content of each particle size of the sample, as shown in Table 1.

Figure 1 shows the particle grading curve on the basis of Table 1. Table 2 shows the characteristic particle size of each sample, including limited particle size $d 60$, average particle

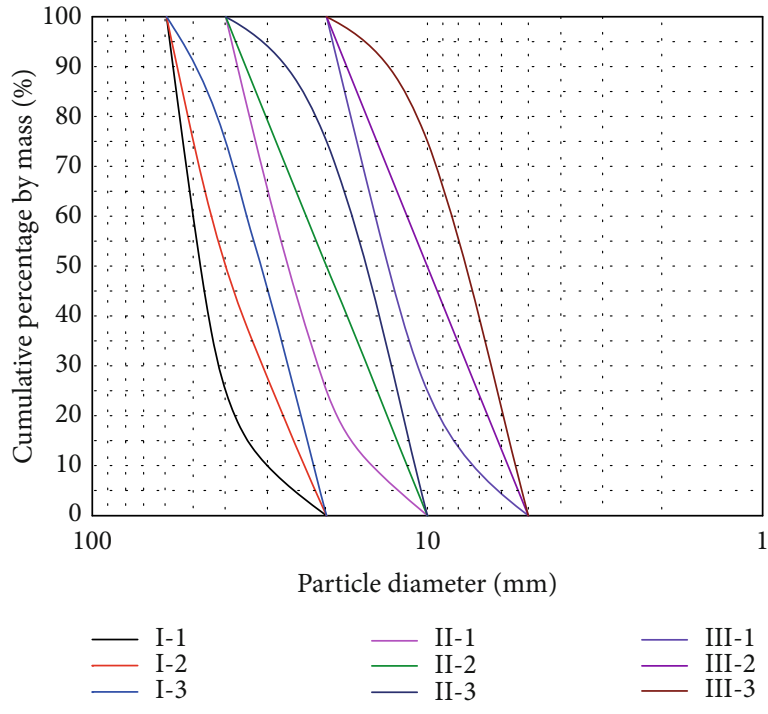

FIGURE 1: Particle grading of gravel samples.

TABLE 2: Characteristic particle size of samples.

\begin{tabular}{lcccc}
\hline $\begin{array}{l}\text { Sample } \\
\text { number }\end{array}$ & $\begin{array}{c}\text { Constrained } \\
\text { grain size } \\
(d 60)(\mathrm{mm})\end{array}$ & $\begin{array}{c}\text { Average } \\
\text { constrained grain } \\
\text { size }(d 50)(\mathrm{mm})\end{array}$ & $\begin{array}{c}d 30 \\
(\mathrm{~mm})\end{array}$ & $\begin{array}{c}\text { Effective } \\
\text { grain size } \\
(d 10)(\mathrm{mm})\end{array}$ \\
\hline I-1 & 50.00 & 47.80 & 42.00 & 30.00 \\
I-2 & 44.10 & 40.00 & 31.00 & 23.30 \\
I-3 & 34.60 & 31.30 & 28.70 & 21.90 \\
II-1 & 28.60 & 26.00 & 21.20 & 14.60 \\
II-2 & 23.00 & 20.00 & 15.10 & 11.50 \\
II-3 & 16.80 & 15.40 & 12.80 & 10.90 \\
III-1 & 14.30 & 13.00 & 10.70 & 7.30 \\
III-2 & 11.50 & 10.00 & 7.60 & 5.75 \\
III-3 & 8.45 & 7.00 & 6.45 & 5.46 \\
\hline
\end{tabular}

size $d 50$, the particle size $d 30$ with a sieving weight accounting to $30 \%$, and effective particle size $d 10$. Nine samples were sheared under four different normal load, and the correlation between characteristic particle size and shear strength parameters was analyzed to explore the influence of particle 


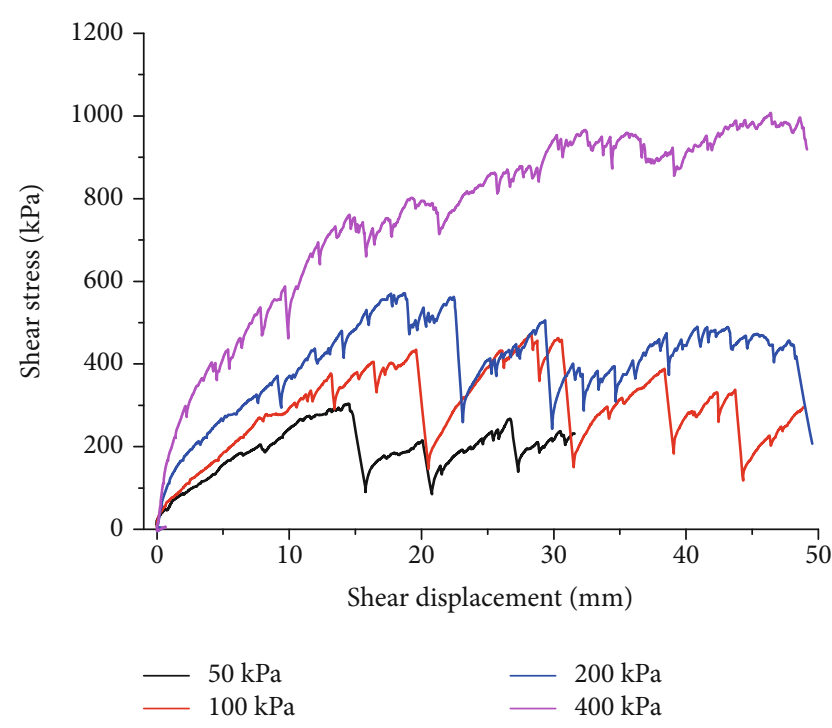

(a) I-1

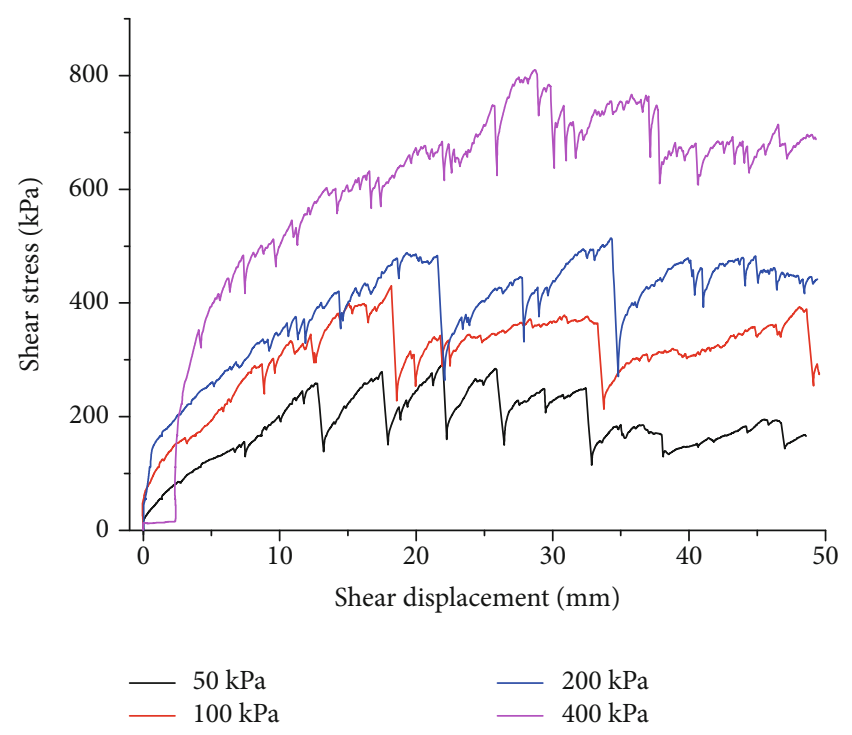

(b) I-2

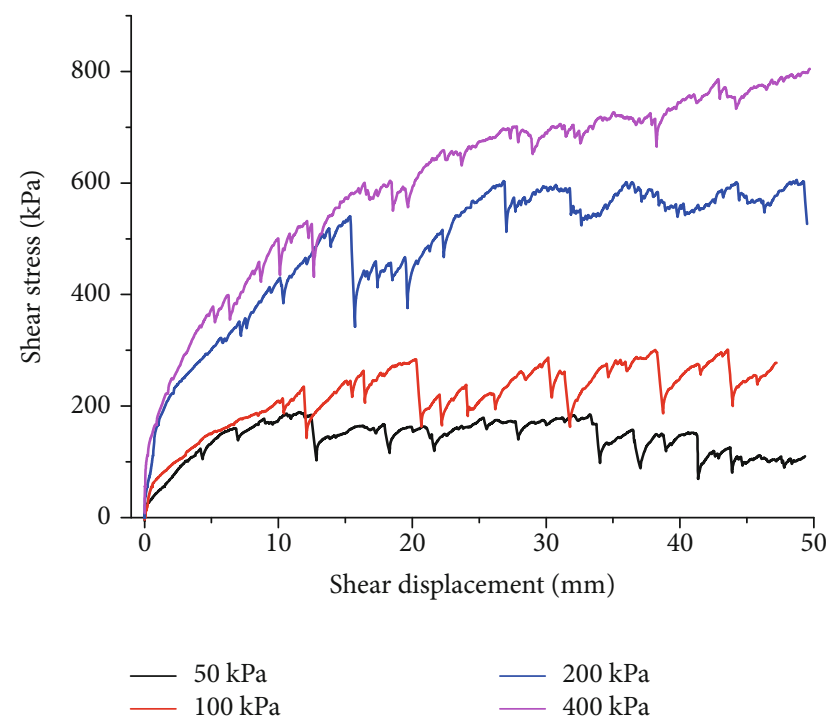

(c) I-3

FIGURE 2: Shear stress versus shear displacement curves of group I (large particle size).

size distribution range on the shear strength characteristics of gravel materials.

2.2. Test Procedure. The particles of each particle grade will be weighed according to the designed particle grade. After being stirred evenly, the particles will be loaded into the shear box in three layers and compacted layer by layer to ensure that the dry density of each sample is consistent and the particles are randomly distributed. The shear rate is $0.1 \mathrm{~mm} / \mathrm{s}$, and each group of samples is tested under a vertical load of $50,100,200$, and $400 \mathrm{kPa}$. The shear stress and displacement are recorded through the data acquisition system, and the test is stopped when shear displacement reaches $50 \mathrm{~mm}$. At the end of the test, the shear plane was observed, and the photos were taken. Moreover, one-third of the samples in the middle of the shear box were rescreened to study the particle breakage characteristic.

\section{Test Results}

3.1. Shear Stress-Tangential Displacement Relationship. Figures 2(a)-2(c), 3(a)-3(c), and 4(a)-4(c) show the shear stress-tangential displacement curves of samples I, II, and III, respectively, obtained from the direct shear test. Two shear failure modes of strain softening and strain hardening in gravel samples are evident. Except for group I, the shear stress-displacement curves of samples are generally a strain softening type. For groups II and III, after reaching the peak of shear stress, the penetration surface has basically formed, with the increase of the tangential displacement; the strength of the material is reduced, so that their failure mode is basically strain softening. As for group I, when the normal load is lower than $200 \mathrm{kPa}$, a peak shear stress occurs, and the failure mode is a strain softening. When the normal load is $400 \mathrm{kPa}$, the shear stress still tends to rise with the advance 


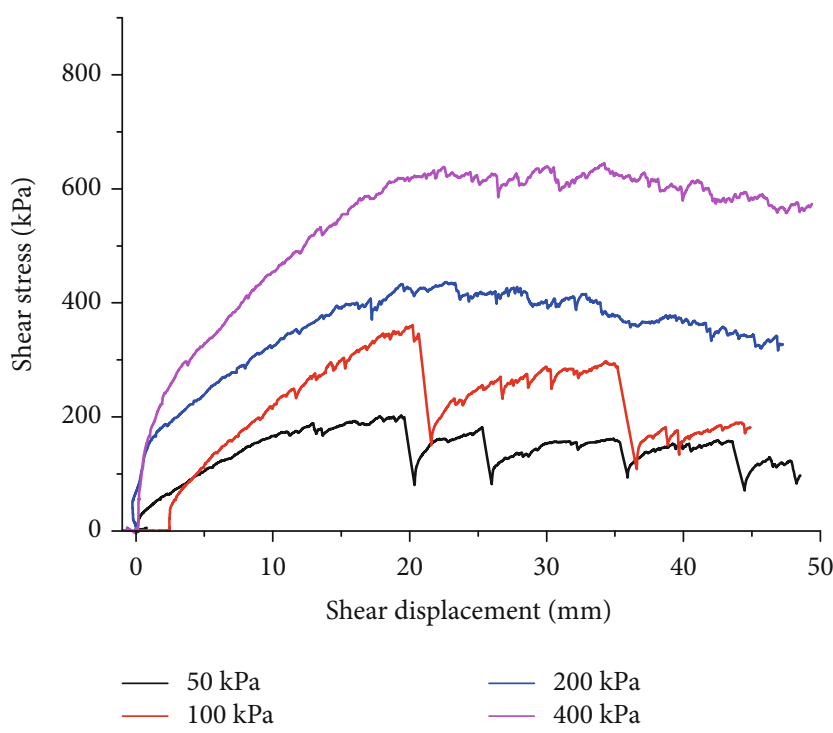

(a) II-1

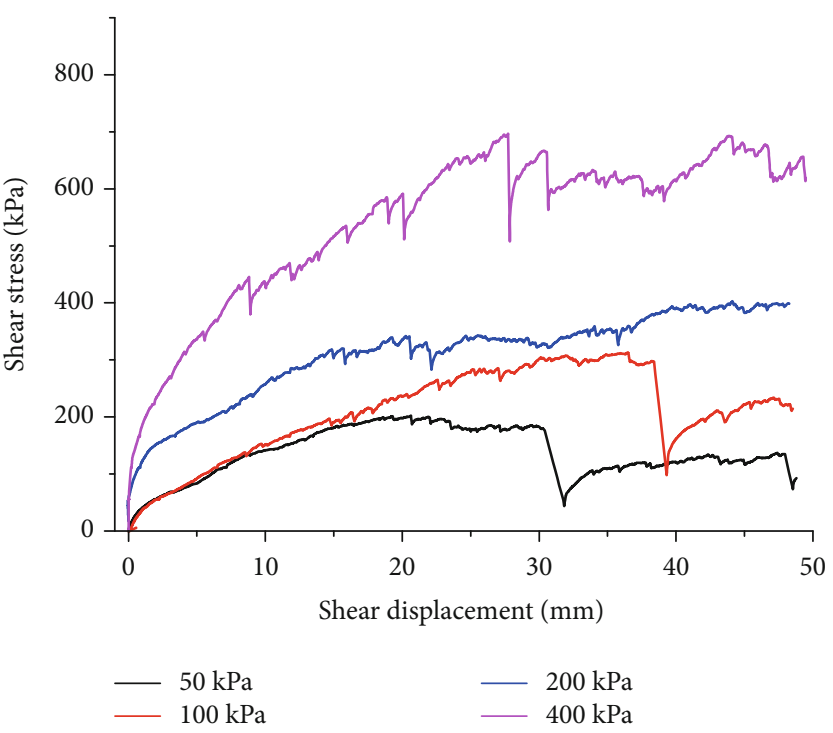

(b) II-2

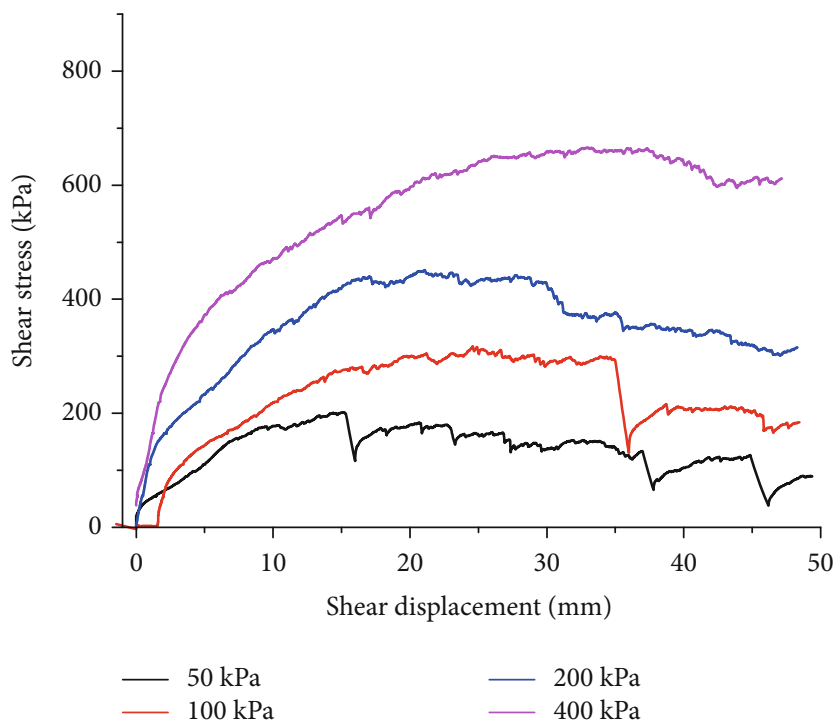

(c) II-3

FIGURE 3: Shear stress versus shear displacement curves of group II (intermediate particle size).

of shear displacement, and the failure mode is strain hardening. That is to say, the compression of high normal load can change the failure mode of the sample.

Under relatively small shear displacement, the shear box has still space for the particles to move and deflect; shear stress increases linearly with the displacement, so the initial shear stress-strain curve is relatively smooth. After the particles are completely compacted, the particles are broken or rearranged by the bite force, which is causing the drop and rise of the curves [23], extremely in groups I and II. The smaller the particle size is, the smaller bite force is, so the shear stress tangential displacement curves of group III have the smallest fluctuation amplitude. When the particle size is small (group III), the fluctuation amplitude of the shear stress tangential displacement curve is also small.
3.2. Normal Load-Shear Strength Relationship. Most of the above shear stress tangential displacement has an evident peak value, so the peak shear stress is taken as the shear strength. For those without peak shear stress, the tangential displacement is taken as $10 \%$ of the sample size [24], that is, the shear stress at $30 \mathrm{~mm}$ is taken as the shear strength, as shown in Table 3.

3.2.1. Stress Ratio. Stress ratio is the ratio of shear strength to normal load. The influence of particle size on the shear strength of the sample is further studied by analyzing the relationship between average particle size of the sample and stress ratio under each normal load, as shown in Figure 5.

With the increase of the sample size, the stress ratio increases step by step, and the jump at $d 50=13 \mathrm{~mm}$ and $d$ 


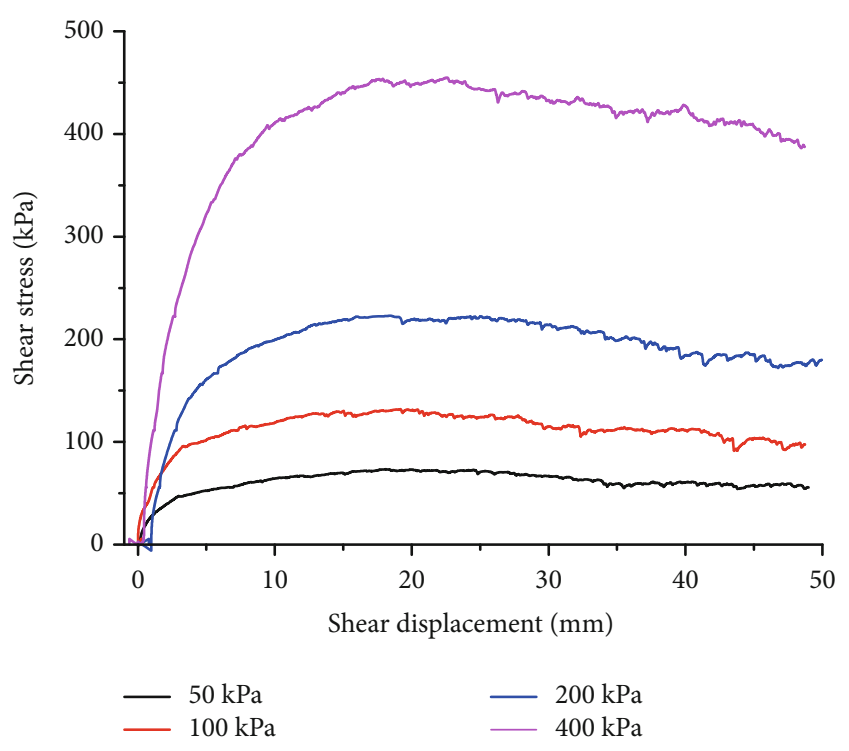

(a) III-1

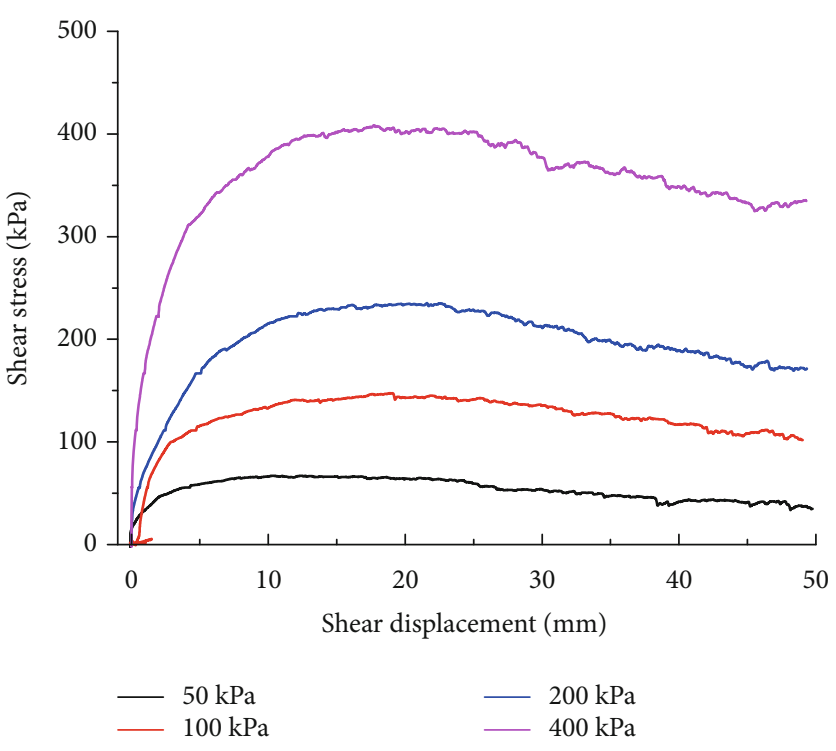

(b) III-2

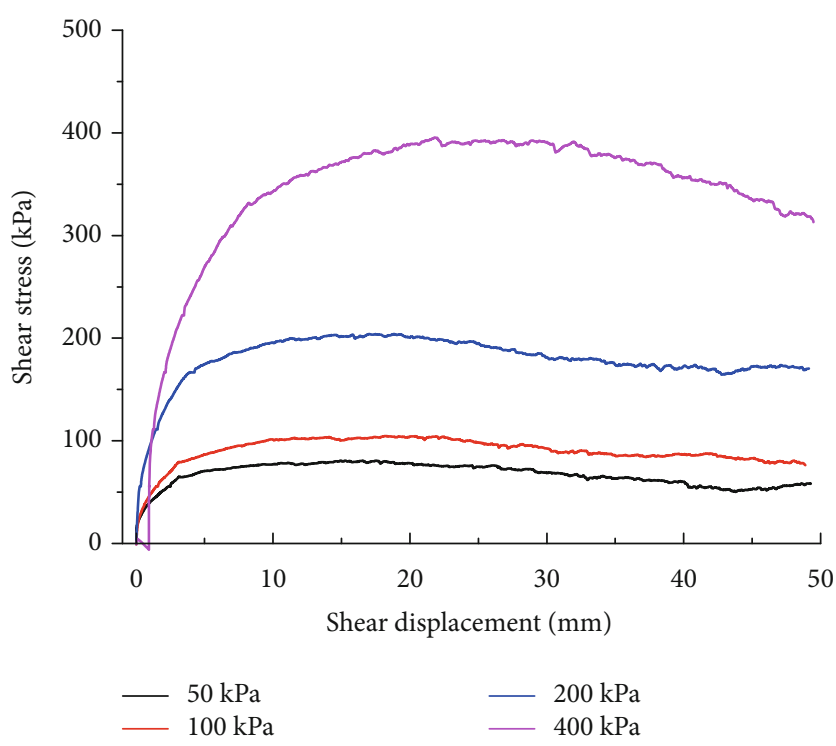

(c) III-3

FIGURE 4: Shear stress versus shear displacement curves of group III (small particle size).

TABLE 3: Shear strength of the sample.

\begin{tabular}{|c|c|c|c|c|c|c|c|c|c|}
\hline \multirow{2}{*}{ Normal load $(\mathrm{kPa})$} & \multicolumn{9}{|c|}{ Shear strength $(\mathrm{kPa})$} \\
\hline & $\mathrm{I}-1$ & $1-2$ & $1-3$ & II-1 & II-2 & II-3 & III-1 & III-2 & III-3 \\
\hline 50 & 303.46 & 291.62 & 189.16 & 202.13 & 201.98 & 203.61 & 73.34 & 67.04 & 80.84 \\
\hline 100 & 473.17 & 430.18 & 301.36 & 361.38 & 312.67 & 320.58 & 131.92 & 147.54 & 104.76 \\
\hline 200 & 570.93 & 513.93 & 605.45 & 436.75 & 402.78 & 455.53 & 222.84 & 235.14 & 204.26 \\
\hline 400 & $1,007.43$ & 810.04 & 689.47 & 645.11 & 696.55 & 672.61 & 454.91 & 408.40 & 395.85 \\
\hline
\end{tabular}

$50=26 \mathrm{~mm}$ has a remarkable relationship with the particle size composition. $d 50$ with $7-13$ and $15.4-26 \mathrm{~mm}$ corresponds to group III and II samples, respectively. The particle size range of the samples is $5-20$ and $10-40 \mathrm{~mm}$, respectively, and the stress ratio of the two sections does not substantially change. In addition, the stress ratio changes with the normal load, that is, the stress effect. In sum, the stress ratio of each specimen decreases with the increase of normal load, and the variation range is inconsistent, which shows that the relationship between shear strength and normal load is nonlinear. 


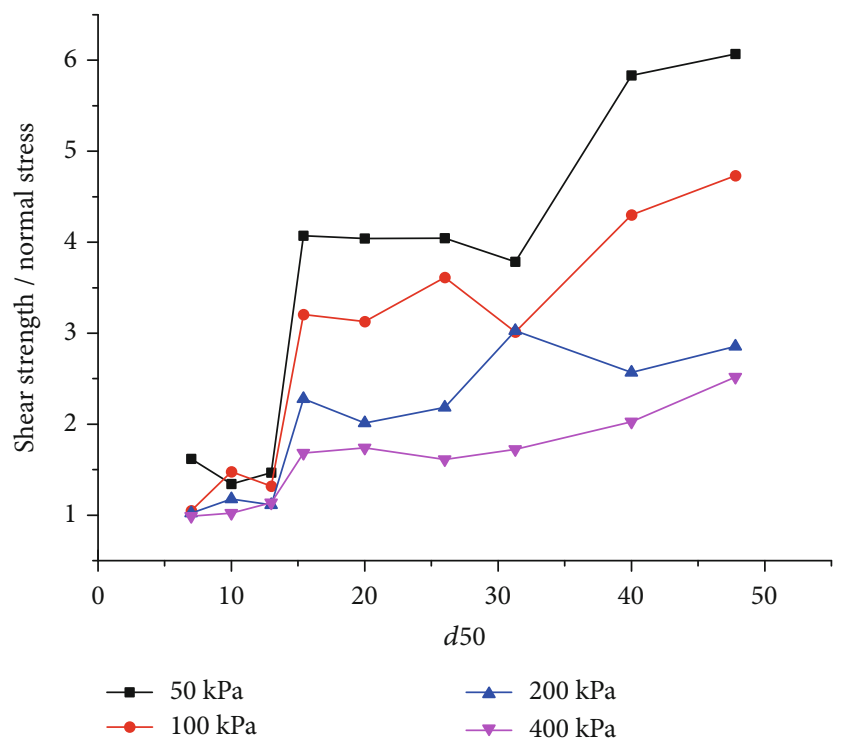

Figure 5: Relationship between stress ratio and $d 50$.

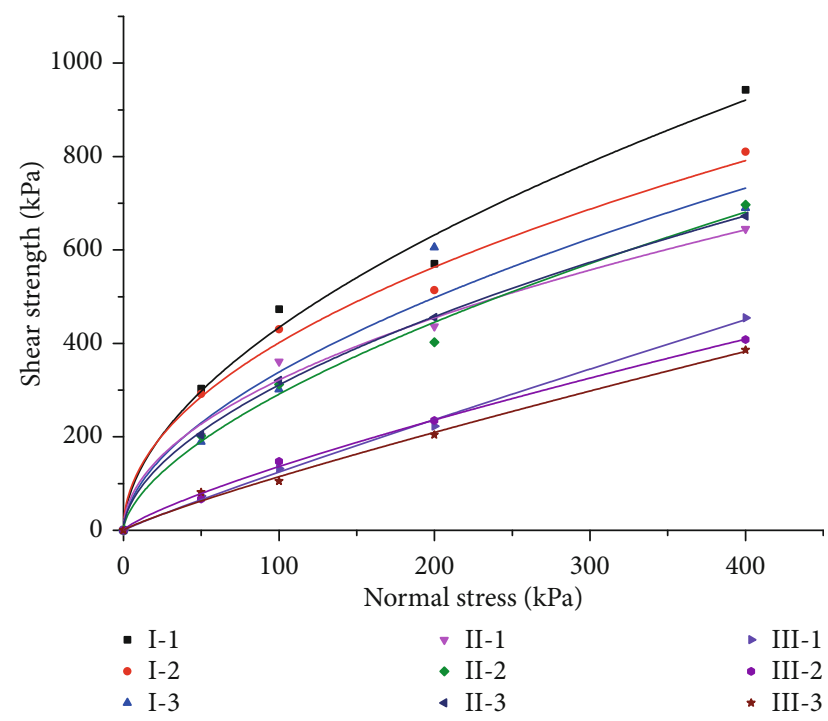

FIGURE 6: Shear strength versus normal load fitting diagram on the basis of power function.

3.2.2. Formula Fitting. Considering that the macromechanical model of soil rock mixture is nonlinear [25-27], it is better to choose the power function strength model to fit the normal load and shear strength relationship of the sample for describing its strength characteristics. Therefore, we select formula (1) that is currently widely used to obtain the normal load-shear stress curve.

$$
\tau=f \sigma_{\mathrm{n}}^{m}+c
$$

where $\tau$ is the shear strength, $\sigma_{\mathrm{n}}$ is the normal load, $f$ is friction coefficient, $m$ is a material parameter, $c$ is cohesion, and when no cohesion exists among particles, $c=0$.

From the results shown in Figure 6, the shear strength of groups I, II, and III decreases with the decrease of particle size
TABLE 4: Shear strength fitting formula and related parameters of each sample.

\begin{tabular}{lcccc}
\hline $\begin{array}{l}\text { Sample } \\
\text { number }\end{array}$ & Fitting formula & $R^{2}$ & $f$ & $m$ \\
\hline I-1 & $\tau=35.72279 \sigma^{0.54232}$ & 0.96039 & 35.72279 & 0.54232 \\
I-2 & $\tau=42.11432 \sigma^{0.48958}$ & 0.96171 & 42.11432 & 0.48958 \\
I-3 & $\tau=26.08094 \sigma^{0.55666}$ & 0.85606 & 26.08094 & 0.55666 \\
II-1 & $\tau=32.19386 \sigma^{0.49982}$ & 0.96233 & 32.19386 & 0.49982 \\
II-2 & $\tau=17.34879 \sigma^{0.61255}$ & 0.97055 & 17.34879 & 0.61255 \\
II-3 & $\tau=23.94237 \sigma^{0.55684}$ & 0.99807 & 23.94237 & 0.55684 \\
III-1 & $\tau=1.74293 \sigma^{0.92716}$ & 0.9941 & 1.74293 & 0.92716 \\
III-2 & $\tau=3.54802 \sigma^{0.79243}$ & 0.99386 & 3.54802 & 0.79243 \\
III-3 & $\tau=2.09252 \sigma^{0.86948}$ & 0.98799 & 2.09252 & 0.86948 \\
\hline
\end{tabular}

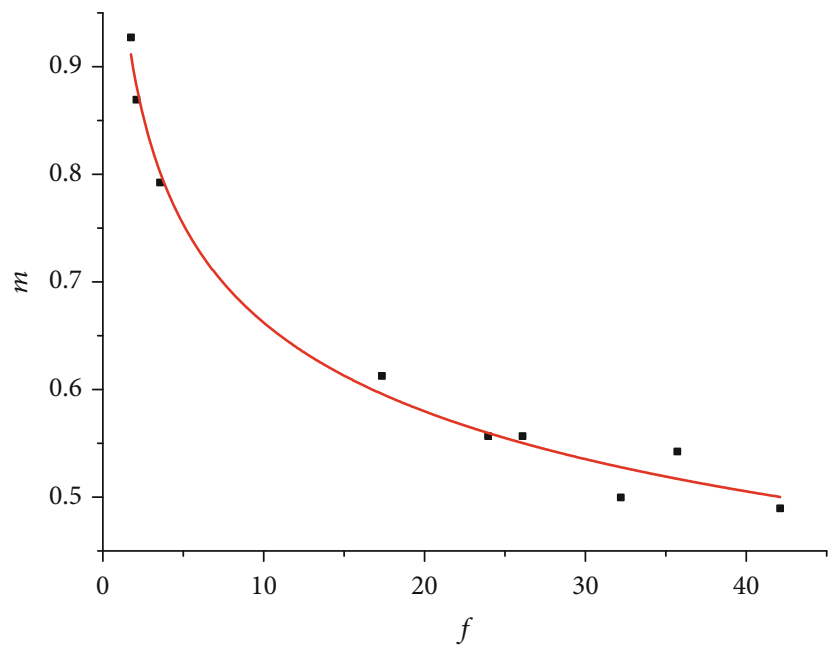

FIgURE 7: Relation curve of $m$ and $f$.

under the same normal load. If the particle size is small, then the exponent $m$ is close to 1 , that is, the fitting curve is close to linearity.

3.2.3. Shear Strength Parameters. Table 4 shows the strength fitting formula and parameters of each sample obtained using formula (1). From the result, it can be found that aside from the fit coefficient $R^{2}$ of sample I- 3 which is $0.85, R^{2}$ of other samples is close to 1 . The fitting effect is good, and the shear strength and normal load of the sample conform to the power function relationship. In addition, a strong correlation is observed between the index $m$ and the friction coefficient $f$, as shown in Figure 7, which can be expressed as a functional relationship:

$$
m=1.184 f^{-0.1488}-0.1783 \text {. }
$$

3.3. Grain Size Effect of Shear Strength. From the above test results, the shear strength characteristics of coarse particles evidently change with the change of particle grading, which is shown as follows: if the particle size of the sample is small, then the shear strength of the sample is low, which shows a 


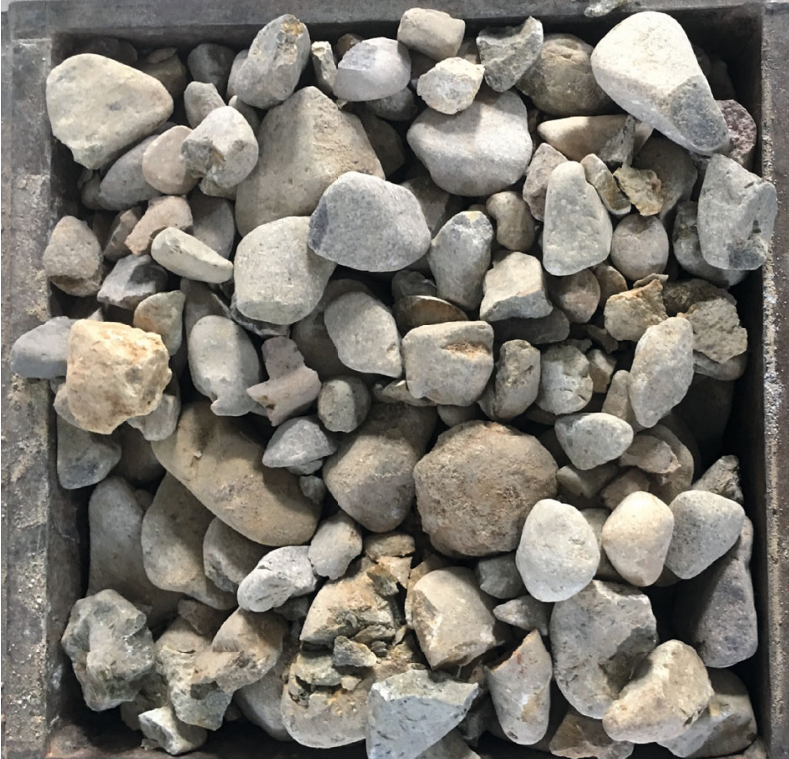

(a) $50 \mathrm{kPa}$

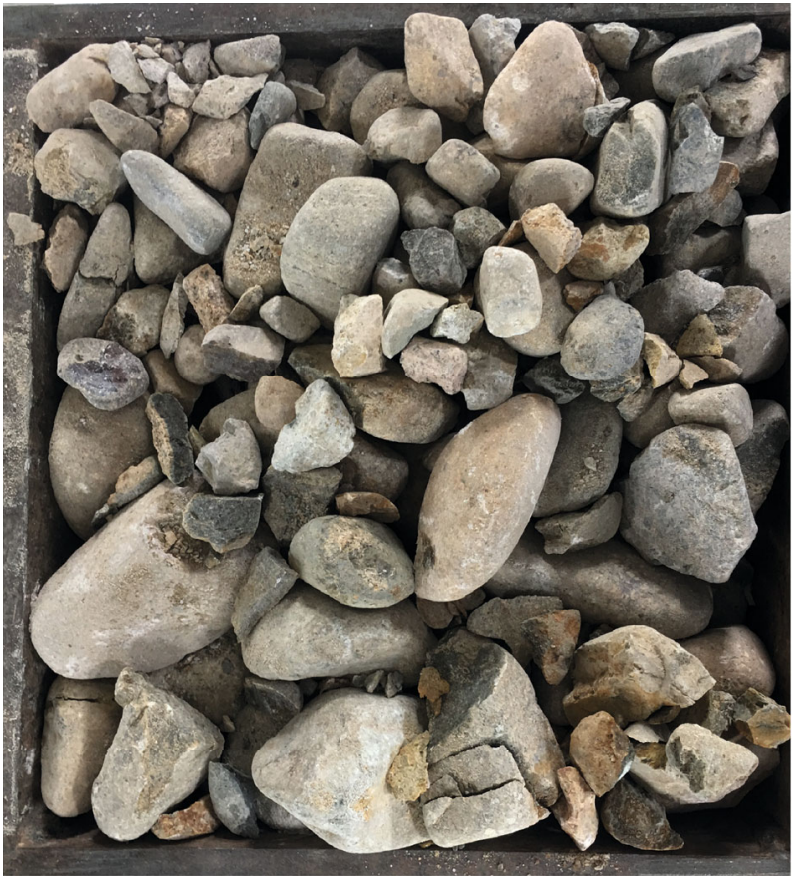

(c) $200 \mathrm{kPa}$

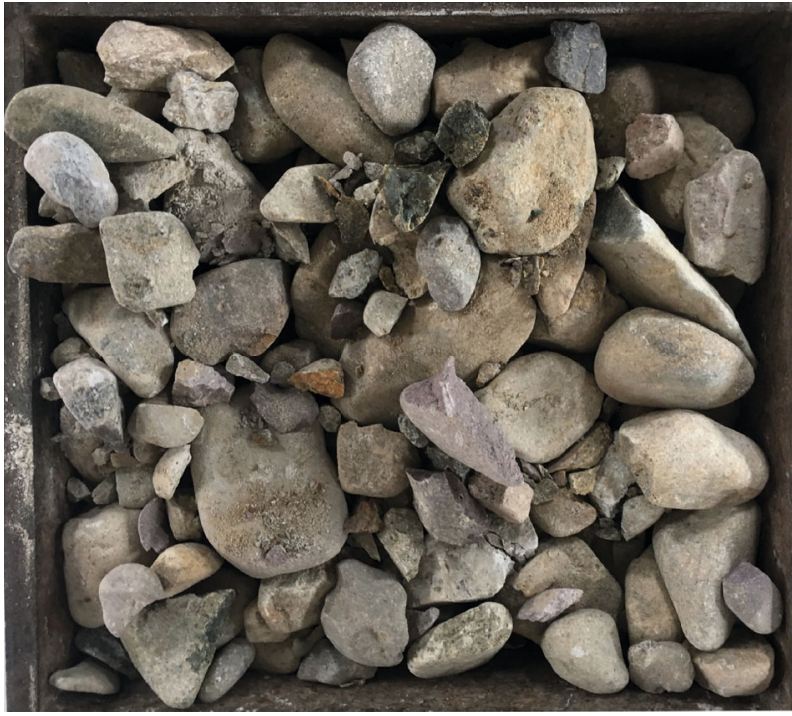

(b) $100 \mathrm{kPa}$

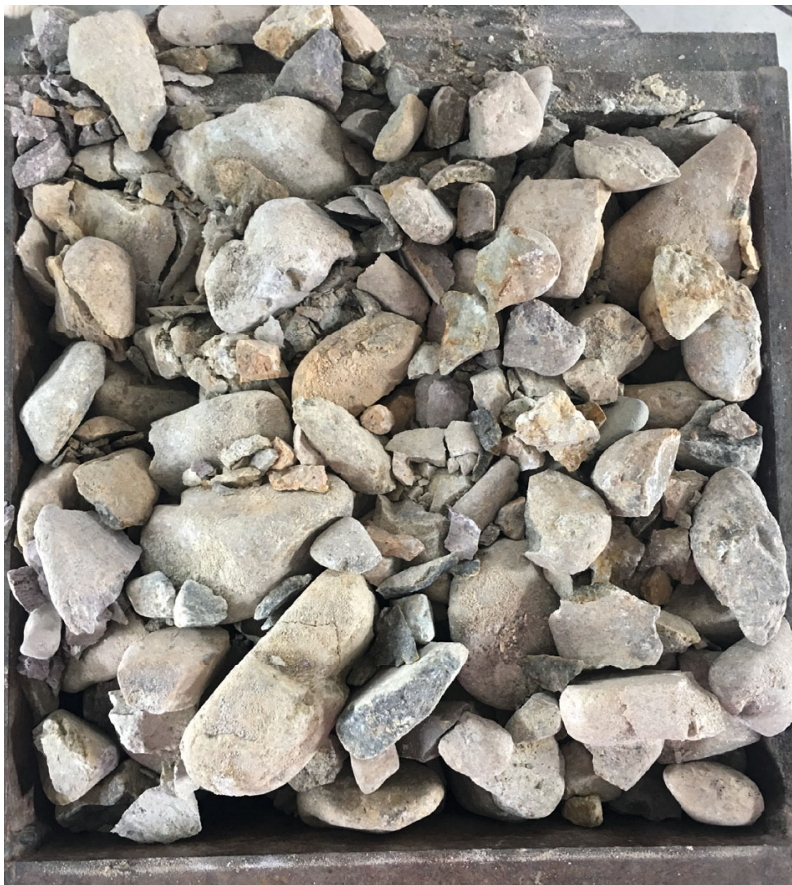

(d) $400 \mathrm{kPa}$

Figure 8: Shear plane of sample I-1 under different normal loads.

certain scale effect. The large particles are embedded deeply in one another, and the displacement and rotation of particles are constrained to a large extent. The particle breakage and structural rearrangement significantly improved the overall macromechanical properties of the sample [28]. On the contrary, the interaction among the small particles is weak, so the strength is low. Through data analysis, the internal relationship between particle gradation characteristics and strength parameters of the sample is further explored.

The sample is composed of multiple particle groups, and the particle grading characteristics of the sample cannot be reasonably expressed by single characteristic particle size. Therefore, the characteristic particle size $d i$ listed in Table 2 is integrated to form the particle grade matching feature collection $D$. A relationship is found between $f$ and $D$ by analyzing their friction coefficient as shown in formula (5). The coefficient $\alpha_{i}$ I is the contribution rate corresponding to the characteristic particle size $d i$, and the coefficient $R^{2}$ is 0.9251 , indicating a relatively high fitting degree.

$$
D=\left[\begin{array}{lllll}
1 & d 10 & d 30 & d 50 & d 60
\end{array}\right],
$$




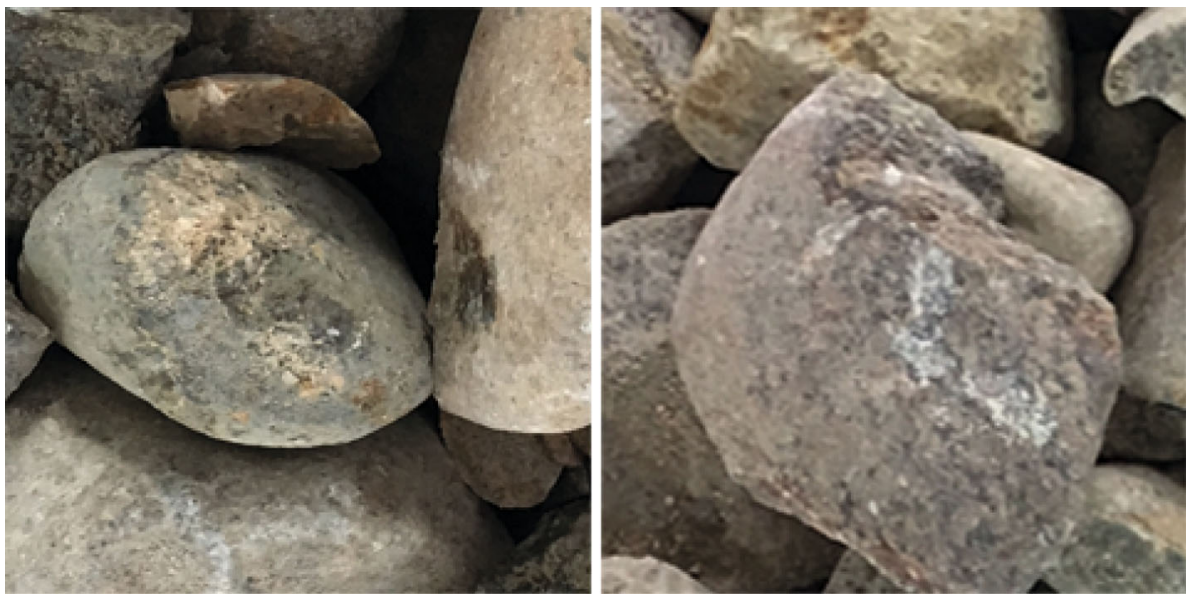

(a) Surface abrasion

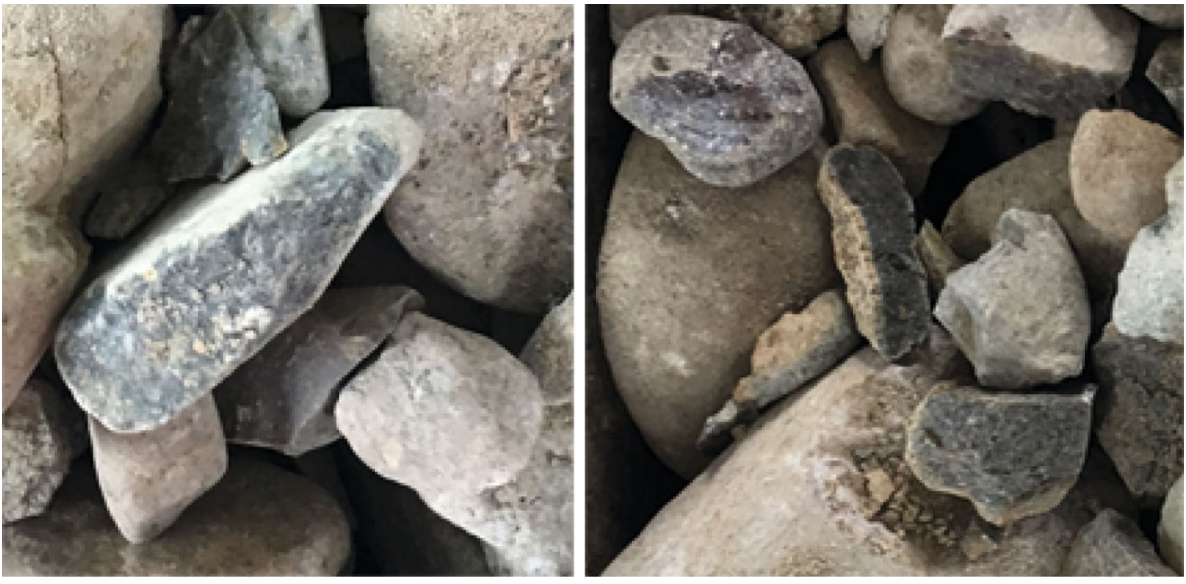

(b) Shearing off
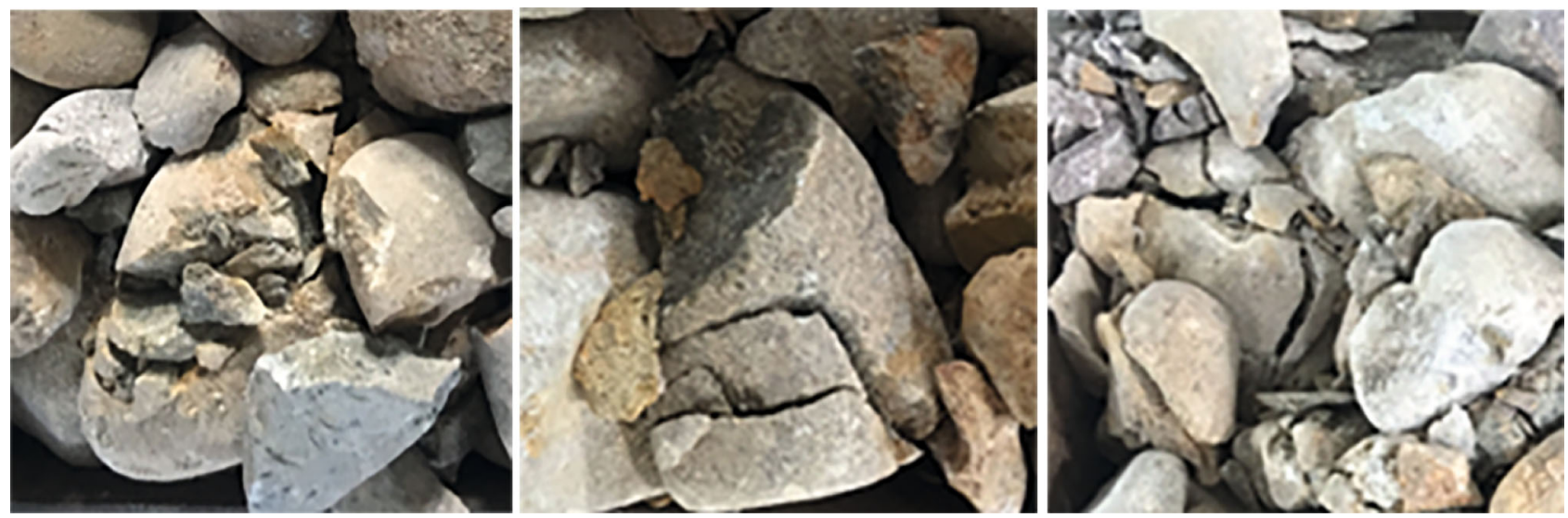

(c) Crushing

FIGURE 9: Shear failure of coarse particles.

$$
A=\left[\begin{array}{lllll}
\alpha_{0} & \alpha_{10} & \alpha_{30} & \alpha_{50} & \alpha_{60}
\end{array}\right]
$$

$$
\begin{aligned}
f=D A^{T}= & {\left[\begin{array}{lllll}
1 & d 10 & d 30 & d 50 & d 60
\end{array}\right] } \\
& {\left[\begin{array}{llllll}
-5.565 & 3.619 & -4.5915 & 2.5397 & 0.1437
\end{array}\right]^{T} . }
\end{aligned}
$$

From formulas (2) and (5), formula (6) can be obtained:

$$
m=1.184\left(D A^{T}\right)^{-0.1488}-0.1783 .
$$

The strength parameters $f$ and $m$ have a specific function relationship with the composition of particle gradation for the gravel material without adhesion among particles. If the 


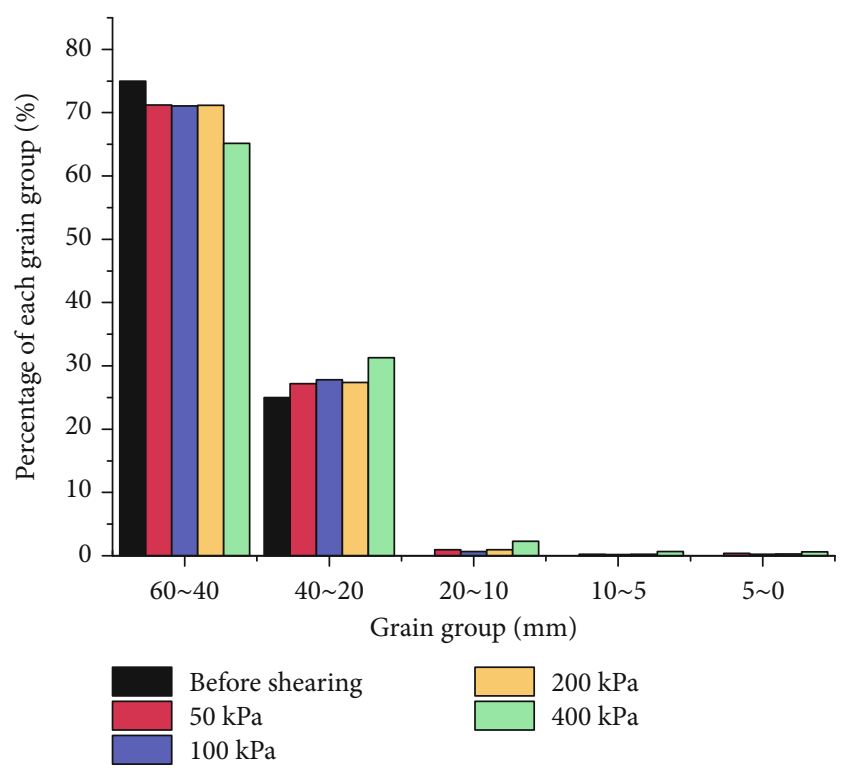

(a) I-1

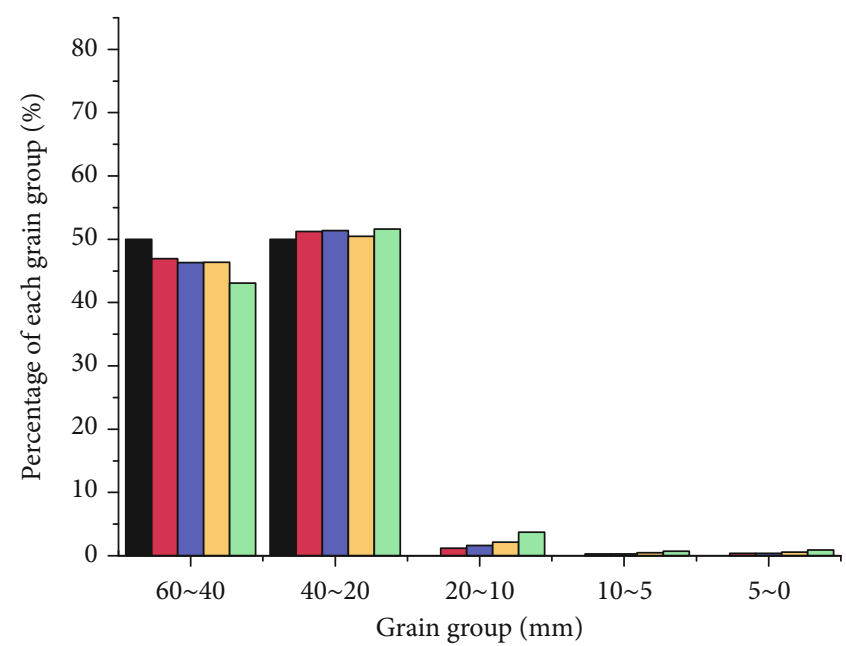

Before shearing $\square 200 \mathrm{kPa}$ $50 \mathrm{kPa} \quad \square 00 \mathrm{kPa}$ $100 \mathrm{kPa}$

(b) I-2

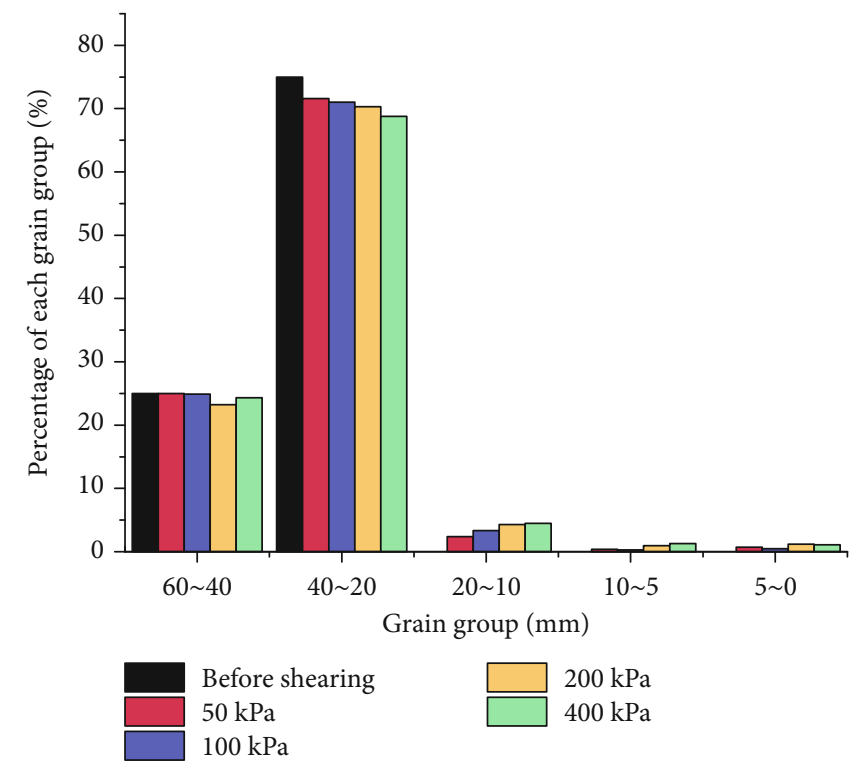

(c) I-3

FIGURE 10: Histogram of contents of each grain group before and after shearing of group I.

overall particle size is large, then the interaction among particles is strong. If the $F$ value is large, then the $m$ value is small, and the shear strength is large.

\section{Analysis}

After the test, the upper shear box was removed while trying not to disturb the particles on the shear plane. The particle breakage characteristic was observed, and the particles $50 \mathrm{~mm}$ above and below the shear plane were extracted for rescreening.

4.1. Particle Breakage Characteristic. The content of 40$60 \mathrm{~mm}$ particles in I-1 sample is high, and the characteristic of particle breakage is easy to distinguish. Therefore, the shear plane of I-1 sample is photographed and analyzed, as shown in Figure 8. Three types of rock shear failure were observed in the failure surface, namely, surface abrasion, shearing off, and crushing, as shown in Figure 9.

Particle breakage characteristic depends on the state of the particles. Under relatively low normal load, most of the particles show surface abrasion, as is shown in Figure 9(a). As for Figure 9(b), shearing off, the cut of the particles is fresh, and the fracture surface is basically parallel to the shear surface. While under the normal load of $400 \mathrm{kPa}$, the particles on the shear plane appear to be crushing by high contact force, as is shown in Figures 8(d) and 9(c).

4.2. Grain Gradation Change. The particles were rescreened after shearing to study and analyze the impact of normal load 


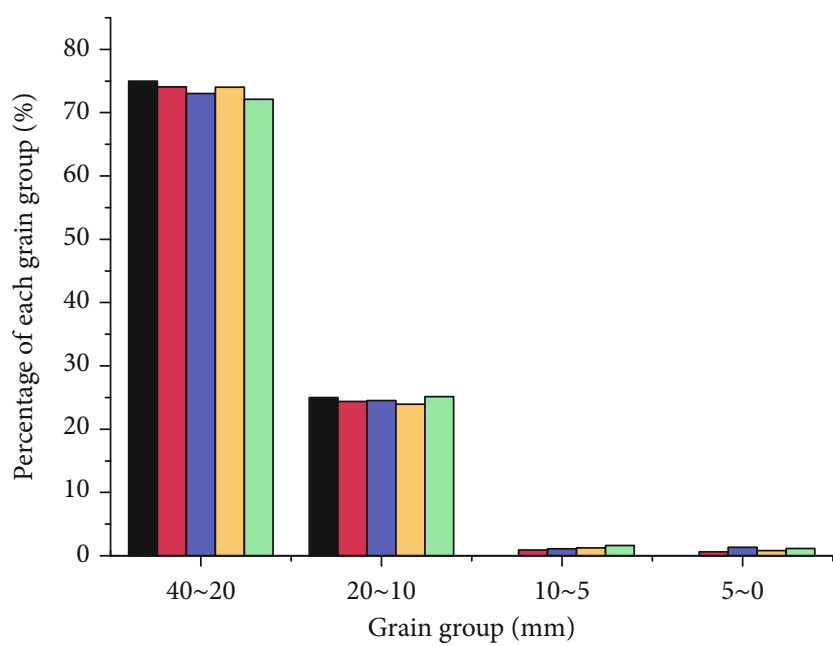

Before shearing $50 \mathrm{kPa}$ $100 \mathrm{kPa}$
$200 \mathrm{kPa}$ $400 \mathrm{kPa}$

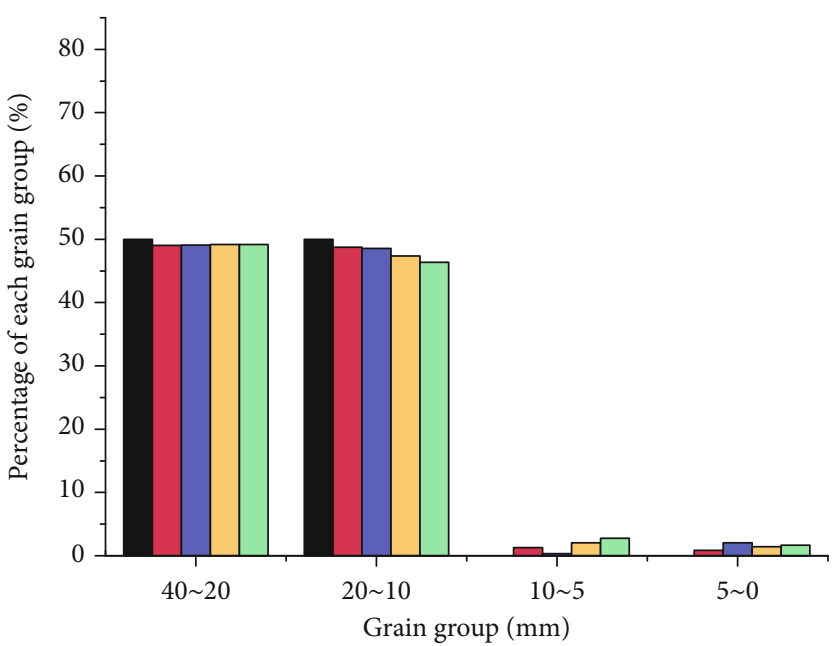

Before shearing $50 \mathrm{kPa}$ $100 \mathrm{kPa}$

(a) II-1

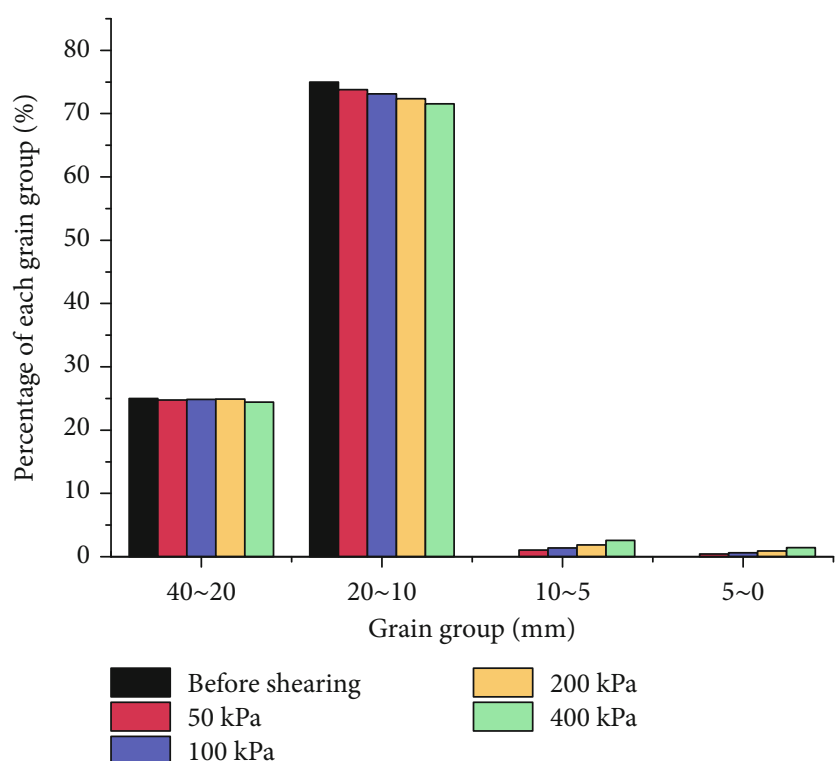

(c) II-3

FIGURE 11: Histogram of contents of each grain group before and after shearing of group II.

and particle size composition on particle breakage of the sample under shearing. Figures 10-12 depict a histogram according to the content of each particle group before and after shearing.

The relative breakage rate $B_{\mathrm{g}}$ proposed by Marsal et al. is introduced to evaluate the particle breakage of the sample [29]:

$$
B_{\mathrm{g}}=\sum \Delta W_{\mathrm{k}}=\sum\left|W_{\mathrm{ki}}-W_{\mathrm{kf}}\right|
$$

where $\sum \Delta W_{\mathrm{k}}$ is the absolute value of the difference between before and after the content test of each particle group; $W_{\mathrm{ki}}$ is the content of a certain particle group before the test; and
$W_{\mathrm{kf}}$ is the content of a certain particle group after the test. The calculation results are shown in Figure 13.

We can see from the figures that, after shearing, the content of large, fine, and intermediate particles decreased, increased, and fluctuated, respectively. Under the shear action, the content of large particles decreases due to breaking into smaller particles, and the content of fine particles increases accordingly. On the one hand, the content of intermediate particles decreases due to breaking into smaller particles; on the other hand, the content of large particles is supplemented due to breaking, so it shows fluctuation change.

When the normal load is large, the change of particle group content is more evident, that is, the higher particle breakage rate is. The constraint of normal load on the sample 


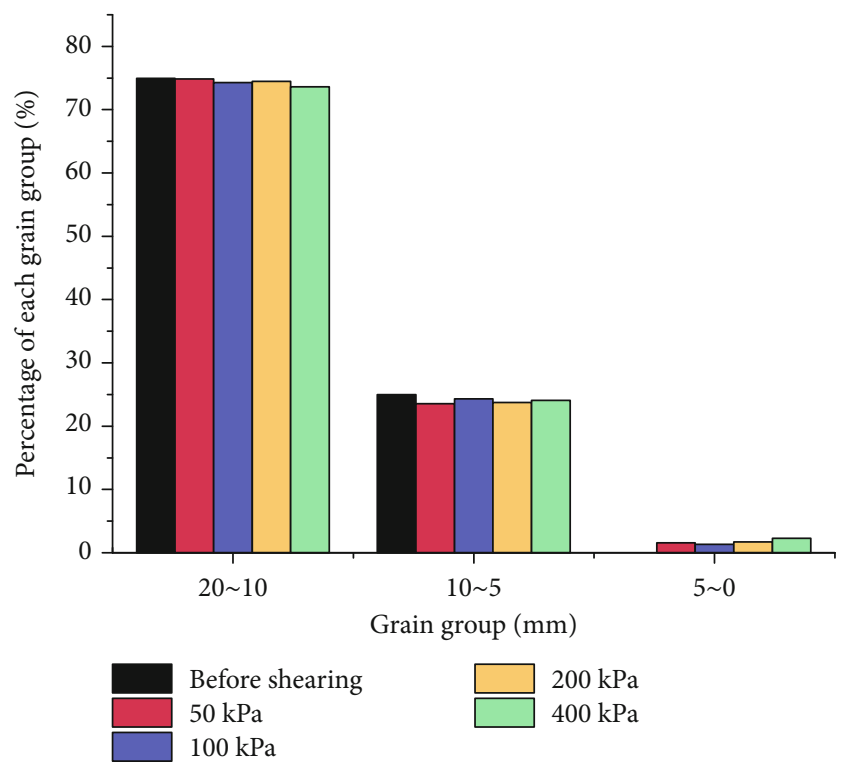

(a) III-1

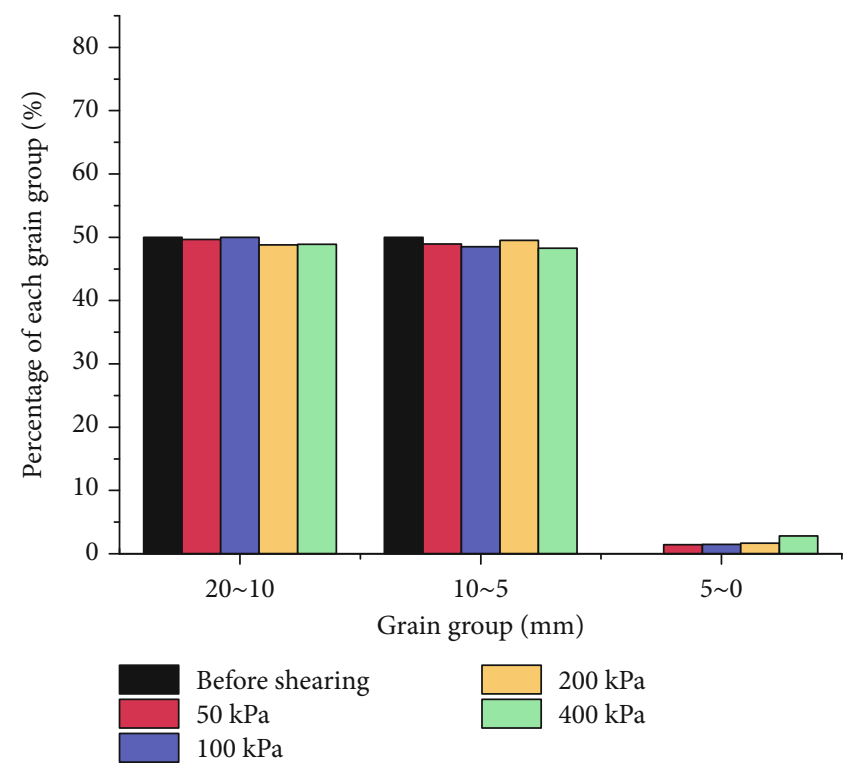

(b) III-2

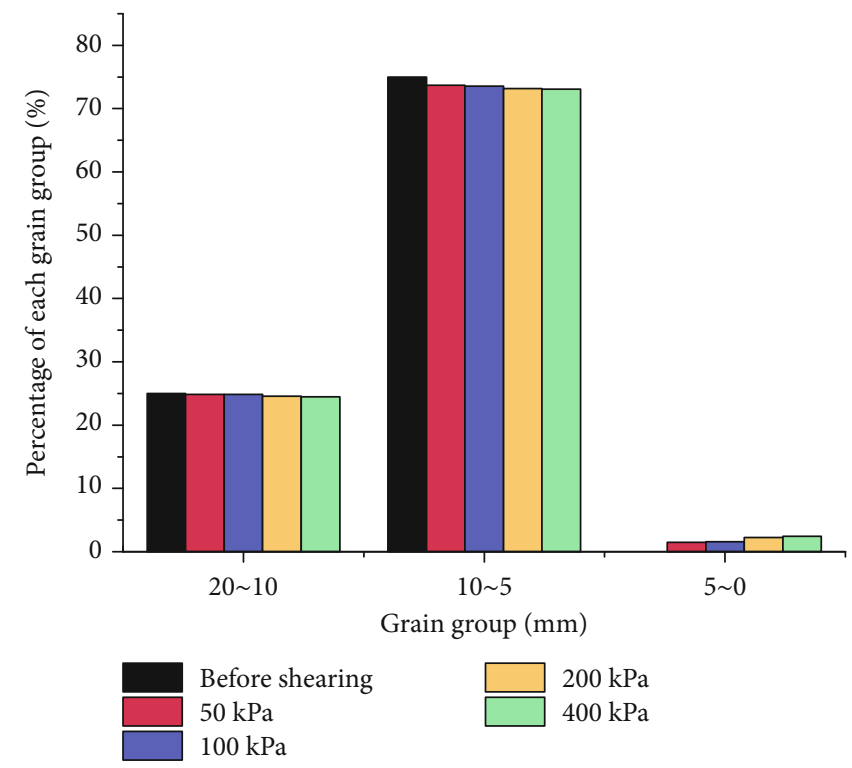

(c) III-3

FIGURE 12: Histogram of contents of each grain group before and after shearing of group III.

oppresses the particles to rotate and cross over, which creates conditions for particle crushing. Moreover, with the increase of normal pressure, the contact force of particles increases, and particles are more likely to be broken.

Under the same normal stress, if the overall particle size is large, then the particle breakage rate is high. When the particle size is large, the number of indirect contacts of particles is relatively small, resulting in a stronger stress concentration effect at the contact point and larger particle breakage. For the third group of samples, the overall particle size of the sample is small, $5-10 \mathrm{~mm}$ particles better fill the gap formed by $10-20 \mathrm{~mm}$ particles, and the point contact stress among particles is more uniform. In the state close to hydrostatic pressure, particles are not easily damaged, so the particle breakage rate is the smallest.

\section{Conclusions}

Through the direct shear test of three particle size ranges and nine groups of coarse-grained samples, the following conclusions are obtained:

(1) The shear stress-displacement curve of coarse particles has peak shear stress, and the failure mode is strain softening. However, for the large size group specimen, the shear stress is still rising, and the failure mode is strain hardening under the high normal load, with the advance of shear displacement. The compaction of high normal load enhances the ability of large size group specimens to resist failure 


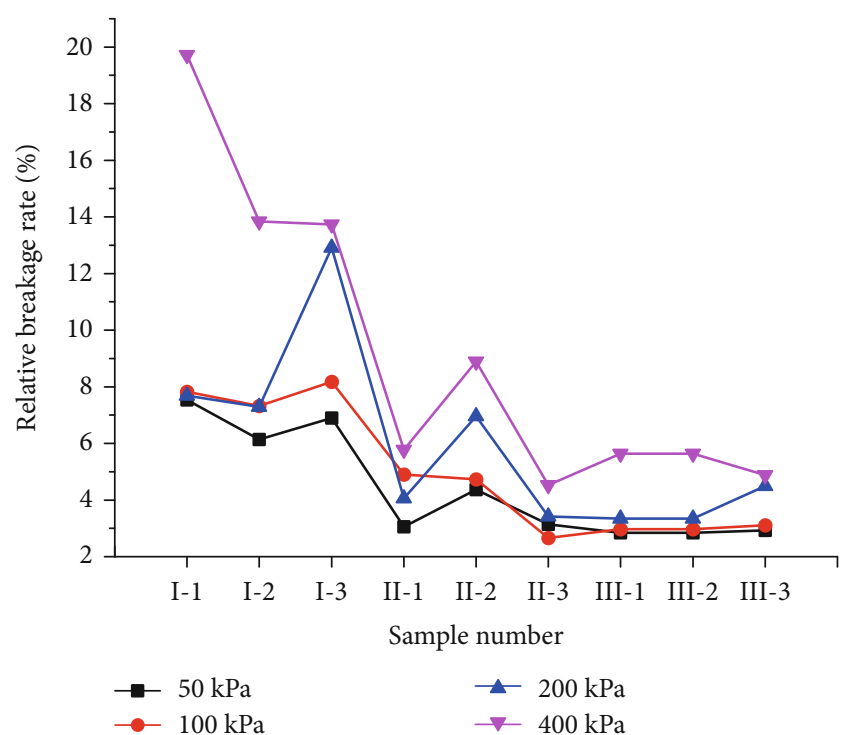

FIGURE 13: Relative breakage rate of each sample.

(2) When the particle size of the sample is large, the shear stress tangential displacement curve fluctuates violently due to the shearing of the particles, which leads to a large " $V$ " jump. When the particle size of the sample is small, the fluctuation range of the shear stress tangential displacement curve is smaller, and the behavior in the shearing process is closer to that of the earth rock mixture

(3) The macromechanical properties of coarse particles are nonlinear, and their strength characteristics conform to the power function strength model due to particle breakage and rearrangement. However, if the particle size is small, the index $m$ is close to 1 , that is, the normal load and shear strength is close to the linear relationship. Index $m$ has a strong correlation with friction coefficient $F$, which can be expressed as $m=1.184 f^{-0.1488}-0.1783$

(4) For the coarse-grained materials without adhesion among particles, a unique relationship exists between the friction coefficient $F$ and the characteristic particle size, which can be expressed as $f=D A^{T}$, where $D$ is the characteristic particle size di to form the particle grade matching feature, and $A$ is the combination of the contribution rate $\alpha_{i}$ corresponding to the characteristic particle size $d i$

(5) The degree of particle breakage is related to the normal load and particle size distribution. For the same sample, if the normal load is high, then the particle breakage rate is high; under the same normal load, if the particle size distribution of the sample is uniform, then the point contact among particles is also uniform. In the state close to the hydrostatic pressure, the particles are not easily destroyed, so the particle breakage rate is lower
In summary, this study provides a preliminary understanding of the shear failure of the gravel material with different particle sizes. Additional tests will be conducted in the future to further explore the mechanical mechanism of gravel material.

\section{Data Availability}

The data used to support the findings of this study are included within the article.

\section{Conflicts of Interest}

The authors declare that there is no conflict of interests regarding the publication of this article.

\section{Acknowledgments}

The study was funded by the Natural Science Foundation of Zhejiang Province (No. LY18D020003) and National Natural Science Foundation of China (Nos. 41327001, 41572299, and 41427802). This support is gratefully acknowledged.

\section{References}

[1] Y. Zhao, Y. Wang, W. Wang, L. Tang, Q. Liu, and G. Cheng, "Modeling of rheological fracture behavior of rock cracks subjected to hydraulic pressure and far field stresses," Theoretical and Applied Fracture Mechanics, vol. 101, pp. 59-66, 2019.

[2] Y. Zhao, L. Zhang, W. Wang, J. Tang, H. Lin, and W. Wan, "Transient pulse test and morphological analysis of single rock fractures," International Journal of Rock Mechanics and Mining Sciences, vol. 91, pp. 139-154, 2017.

[3] Y. Wang, H. Zhang, H. Lin, Y. Zhao, and Y. Liu, "Fracture behaviour of central-flawed rock plate under uniaxial compression," Theoretical and Applied Fracture Mechanics, vol. 106, p. 102503, 2020.

[4] H. Lin, H. Yang, Y. Wang, Y. Zhao, and R. Cao, "Determination of the stress field and crack initiation angle of an open flaw tip under uniaxial compression," Theoretical and Applied Fracture Mechanics, vol. 104, p. 102358, 2019.

[5] S. Xie, H. Lin, Y. Chen, R. Yong, W. Xiong, and S. du, "A damage constitutive model for shear behavior of joints based on determination of the yield point," International Journal of Rock Mechanics and Mining Sciences, vol. 128, p. 104269, 2020.

[6] H. Lin, W. Xiong, and Q. Yan, "Modified formula for the tensile strength as obtained by the flattened Brazilian disk test," Rock Mechanics and Rock Engineering, vol. 49, no. 4, pp. 1579-1586, 2016.

[7] R. Cao, P. Cao, X. Fan, X. Xiong, and H. Lin, “An experimental and numerical study on mechanical behavior of ubiquitousjoint brittle rock-like specimens under uniaxial compression," Rock Mechanics and Rock Engineering, vol. 49, no. 11, pp. 4319-4338, 2016.

[8] R.-H. Cao, P. Cao, H. Lin, C.-Z. Pu, and K. Ou, "Mechanical behavior of brittle rock-like specimens with pre-existing fissures under uniaxial loading: experimental studies and particle mechanics approach," Rock Mechanics and Rock Engineering, vol. 49, no. 3, pp. 763-783, 2016. 
[9] N. Barton and V. Choubey, "The shear strength of rock joints in theory and practice," Rock Mechanics, vol. 10, no. 1-2, pp. 1$54,1977$.

[10] G. Grasselli, J. Wirth, and P. Egger, "Quantitative threedimensional description of a rough surface and parameter evolution with shearing," International Journal of Rock Mechanics and Mining Sciences, vol. 39, no. 6, pp. 789-800, 2002.

[11] C. C. Xia, Z. C. Tang, W. M. Xiao, and Y. L. Song, "New peak shear strength criterion of rock joints based on quantified surface description," Rock Mechanics and Rock Engineering, vol. 47, no. 2, pp. 387-400, 2014.

[12] G. Wang, C. Yang, C. Zhang, H. Mao, and W. Wang, "Experimental research on particle breakage and strength characteristics of rock and soil materials with different coarse-grain contents," Rock and Soil Mechanics, vol. 30, no. 12, pp. 3649-3654, 2009.

[13] Y. Xiao, H. L. Liu, X. M. Ding, Y. Chen, J. Jiang, and Wengang Zhang, "Influence of particle breakage on critical state line of rockfill material," International Journal of Geomechanics, vol. 16, no. 1, article 04015031, 2016.

[14] Y. Zhao, L. Zhang, W. Wang et al., "Creep behavior of intact and cracked limestone under multi-level loading and unloading cycles," Rock Mechanics and Rock Engineering, vol. 50, no. 6, pp. 1409-1424, 2017.

[15] X. Chang, G. Ma, W. Zhou, and C. Zhou, "Influences of particle shape and inter-particle friction angle on macroscopic response of rockfill," Chinese Journal of Geotechnical Engineering, vol. 34, no. 4, pp. 646-653, 2012.

[16] N. Stark, A. E. Hay, R. Cheel, and C. B. Lake, "The impact of particle shape on friction angle and resulting critical shear stress: an example from a coarse-grained, steep, megatidal beach," Earth Surface Dynamics Discussions, vol. 1, no. 1, pp. 1187-1208, 2013.

[17] K. Y. Kim, H. S. Suh, T. S. Yun, S. W. Moon, and Y. S. Seo, "Effect of particle shape on the shear strength of fault gouge," Geosciences Journal, vol. 20, no. 3, pp. 351-359, 2016.

[18] M. Afifipour and P. Moarefvand, "Mechanical behavior of bimrocks having high rock block proportion," International Journal of Rock Mechanics and Mining Sciences, vol. 65, pp. 40-48, 2014.

[19] J. M. Buffington, W. E. Dietrich, and J. W. Kirchner, "Friction angle measurements on a naturally formed gravel streambed: implications for critical boundary shear stress," Water Resources Research, vol. 28, no. 2, pp. 411-425, 1992.

[20] C. Tuitz, U. Exner, A. Preh, and B. Grasemann, "The influence of particle orientation on the loading condition of pebbles in fluvial gravel," Granular Matter, vol. 14, pp. 639-649, 2012.

[21] T. Zhao, W. Zhou, X. Chang, G. Ma, and X. Ma, "Fractal characteristics and scaling effect of the scaling method for rockfill materials," Rock and Soil Mechanics, vol. 36, no. 4, pp. 1093-1101, 2015.

[22] L. Wu, S. Zhu, X. Zhang, and W. Chen, "Analysis of scale effect of coarse-grained materials," Rock and Soil Mechanics, vol. 37, no. 8, pp. 2187-2197, 2016.

[23] J. M. Ting, L. Meachum, and J. D. Rowell, "Effect of particle shape on the strength and deformation mechanisms of ellipse-shaped granular assemblages," Engineering Computations, vol. 12, no. 2, pp. 99-108, 1995.
[24] National Development and Reform Commission and PRC, Code for coarse-grained soil for hydropower and water conservancy engineering, China Electric Power Press, Beijing, 2007.

[25] V. F. B. De Mello, "Reflections on design decisions of practical significance to embankment dams," Geotechnique, vol. 27, no. 3, pp. 281-355, 1977.

[26] X. Liu, Y. Tu, P. Wang, Z. Zhong, W. Tang, and L. Du, "Particle breakage of soil-rock aggregate based on large-scale direct shear tests," Chinese Journal of Geotechnical Engineering, vol. 39, no. 8, pp. 1425-1434, 2017.

[27] H. Z. Wei, W. J. Xu, C. F. Wei, and Q. S. Meng, "Influence of water content and shear rate on the mechanical behavior of soil-rock mixtures," SCIENCE CHINA Technological Sciences, vol. 61, no. 8, pp. 1127-1136, 2018.

[28] A. Hamidi, M. Alizadeh, and S. M. Soleimani, "Effect of particle crushing on shear strength and dilation characteristics of sand-gravel mixtures," International Journal of Civil Engineering, vol. 7, no. 1, pp. 61-71, 2009.

[29] R. J. Marsal, "Mechanical properties of rockfill Embankment Dam engineering," in Casagrande Volume, pp. 109-200, Wiley, New York, 1973. 